\title{
EVALUASI PEMBELAJARAN SERTA PENGARUHNYA TERHADAP MINAT BELAJAR PADA MATA PEMBELAJARAN IPA SISWA KELAS IX SMPN 3 TANJUNG SAKTI PUMI LAHAT SUMATRA SELATAN
}

\author{
Dewy Widiyawati, Cici Dwi Putri, Ahmad Walid \\ Prodi Tadris Ilmu Pengetahuan Alam Institut Agama Islam Negeri Bengkulu \\ Email: dewywidiyawati99@gmail.com, cicidwiputri855@gmail.com, \\ dongawalid19@gmail.com
}

Website : https://jurnal.uin-antasari.ac.id/index.php/ptkpend/index

Received: 17 Desember 2020; Accepted: 1 Januari 2021; Published: 1 Januari 2021

\begin{abstract}
The purpose of this study is to determine the extent to which students can achieve their learning objectives in science learning and to see the role and interest of students in science lessons at school. This research uses a qualitative approach, with a descriptive type of research. The results of this study indicate that the implementation of learning evaluation at the first 3 secondary school in Tanjung Sakti Pumi Lahat, South Sumatra based on preliminary observations obtained $75 \%$ students have been able to reach the average standard of learning and there are also some students who have not reached the average standard.
\end{abstract}

Key Words: Learning Evaluatioan; Natural Science Learning

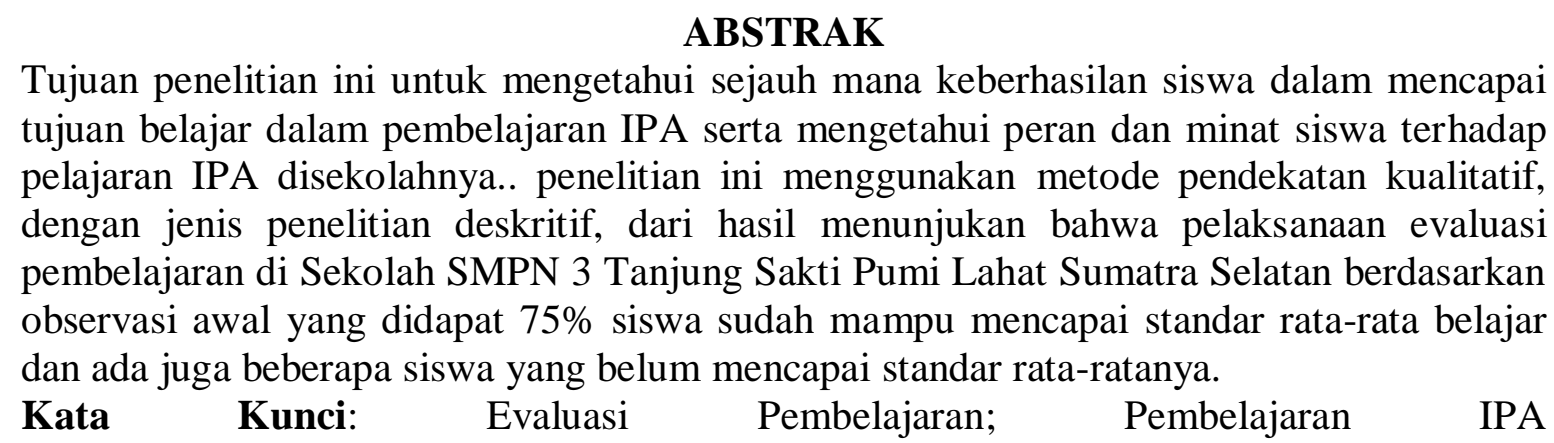

\section{PENDAHULUAN}

Pelaksanaan pembelajaran IPA merupakan tugas para guru IPA dan yang paling penting tujuan guru yaitu untuk merubah pola pikir, sikap serta keterampilan peserta didik dalam proses belajar mengajar yang menjadi fokus utama guru yaitu peserta didik. Tidak semua guru melakukan pembelajaran yang berpusat pada peserta didik, masih banyak guru melakukan proses pembelajaran yang berpusat pada guru, peserta didik menjadi pendengar yang baik.

IPA merupakan pembelajaran ilmu pengetahuan alam tentang objek serta gejala-gejalanya. IPA sebagai proses yang dikenal dengan metode ilmiah. Di samping itu, IPA juga memiliki nilai-nilai ilmiah atau value of science yang melekat pada pengetahuan ilmiah (Paramata, 2001)

Dengan kata lain proses belajar mengajar belum diketahui berhasil 
tidaknya sebelum evaluasi dilakukan. Karena itu evaluasi harus diperlukan dalam proses belajar mengajar. Dengan evaluasi yang baik, dan menyeluruhakan dapat mengetahui apa yang di inginkan dari kegiatan belajar mengajar. Didalam proses belajar mengajar peran guru sangat penting dalam keberhasilan suatu pembelajaran. Pembelajaran yang sebelumnya lebih menitik beratkan pada peran guru, fasilitator, instruktur yang semakin besar, dalam perjalanannya peserta didik atau siswa dalam mengambil inisiatif dan partisipasi di dalam kegiatan belajar (Aunurrahman, 2009).

Didalam suatu proses belajar mengajar yang terjadi didalam kelas, tentu sistem evaluasi pembelajaran yang dilakukan oleh guru terhadap bagaimana perkembangan peserta didiknya akan sangat penting. Apabila suatu pembelajran yang dilakukan oleh guru tersebut mampu mengembangkan potensi dari peserta didiknya, maka hal tersebut mampu mengembangkan potensi diri peserta didik atas pencapaian yang telah dilakukan oleh guru atau dengan mengetas peserta didik (Wahyu, 2015). Tes merupakan pengumpulan informasi (Zuhud, 1995)

Proses pembelajaran tersebut adalah upaya mempelajarkan siswa oleh guru agar mampu belajar aktif mengonstruksi kecekapan hidup yang baik yang bersifat kognitif, afektif, maupun konatif secara mandiri, masyarakat belajar aktif sebagai cara membelajarkan siswa yang membuat siswa berpartisipasi didalam kelas. (Paulson \& Faust, 2002).

Prinsip belajar aktif berakar dari teori belajar konstruktivisme, salah satunya utamanya adalah Piaget sendiri. Menurut teori kontruktivisme pusat pembelajaran bukanlah guru tetapi dari siswa itu sendiri. Strategi pembelajaran ini disebut student centered instruction (Slavin, 2000).

Evaluasi merupakan proses

kelanjutan untuk menentukan kualitas nilai dan arti dari sesuatu, berdasarkan pertimbangan dan kriteria tertentu dalam rangka membuat keputusan dan aspekaspek hendak dinilai ditetapkan sebelumnya agar guru mempunyai pedoman di dalam melaksanakan penilaiannya. (Nuriyah, 2014).

Dalam proses belajar mengajar evaluasi merupakan suatu faktor yang sangat penting karena dapat menimbulkan minat belajar pada siswa dan akan jika gurunya mampu memberikan evaluasi yang secara sedehana dan mudah dimengerti oleh peserta didiknya maka dari itu pembelajaran di dalam kelas terasa hidup.

\section{METODE PENELITIAN}

Dalam penelitian ini menggunakan metode pendekatan kualitatif, dengan jenis penelitian deskritif. Penelitian ini mendeskripsikan dan mengevaluasi pembelajaran IPA. Sumber penelitian ini adalah guru IPA, dan murid kelas IX yang dimana didalam kelas tersebut terdapat 8 orang siswa dan diambil 2 orang siswa sebagai sampel. Sumber hasil dari penelitian ini adalah wawancara, dokumentasi berupa foto-foto kegiatan pelaksanaan penelitian dari awal sampai akhir penelitian dan nilai hasil UTS dari siswa-siswinya.

Penelitian ini dilakukan di SMPN 3 Tanjung Sakti Pumi Lahat Sumatra Selatan dan teknik pengambilan penelitian ini yaitu hasil dari wawancara serta hasil UTS kelas IX.

Intrumen penelitian ini yaitu berupa observasi awal, wawancara, dokumentasi dan hasil nilai UTS. Alat pendukung berupa kamera untuk mengambil sesi dokumentais dan alat perekam suara untuk wawancaranya.

\section{HASIL DAN PEMBAHASAN}

\section{A. Hasil evaluasi dalam pembelajaran IPA}

Evalusi adalah suatu kegiatan yan berkenaan terhadap proses untuk melakukan suatu penilaian terhadap berbagai hal. 
Dari observasi awal yang dilakukan terhadap guru dan 8 orang peserta didik di SMPN 3 Tanjung Sakti Pumi Lahat Sumatra Selatan untuk tahun ajaran 2020/2021, bahwa hasil evaluasi dalam pembelajaran IPA yang dilakukan oleh guru pada siswa dilakukan untuk menilai serta mengetahui sejauh mana keberhasilan siswa dalam mencapai tujuan belajar tersebut.

\section{B. Minat siswa dalam pembelajaran IPA}

Minat merupakan suatu perlakukan yang ikhlas tanpa adanya suatu paksaan atau dorongan dari pihak lain.

Dari hasil wawancara kepada guru dan siswa wawancara yang didapatkan bahwa guru menganggap jika para guru menggunakan cara pembelajaran yang lebih modern dalam proses belajar mengajar dan melibatkan siswa secara langsung para siswa merasa bosan dalam proses pembelajaran.

Dari hasil wawancara dengan beberapa siswa sebagian siswa berminat dalam mempelajari mata pelajaran IPA yang diajarkan oleh para guru dengan alasan guru lebih banyak menggunakan metode ceramah atau bercerita kepada para siswa dan tidak adanya media pembelajaran yang mendukung dalam praktikum dan observasi, sehingga bagi para siswa sulit untuk memahami konsep yang disampaikan para guru.

Sehingga untuk membuat siswa yang kurang berminat menjadi suka dalam pembelajaran IPA, yaitu dengan cara

Table Daftar nilai hasil Ulangan tengah semester kelas IX di SMPN 3 Tanjung Sakti Pumi Lahat Sumatra Selatan melakukan pendekatan personal dan memahami gaya belajar siswa tersebut serta memberikan kebebasan dalam arti kebebasan yang terkontrol supaya siswa berani aktif dalam pembelajaran. Kemudian untuk menarik minat belajar pada peserta didik, hal utama yang para guru lakukan yaitu harus mampu membaca pola pikir belajar para siswa itu sendiri.

\section{Menarik minat siswa dalam pembelajaran IPA}

Dalam menarik minat siswa dalam belajar biasanya melakukan berbagai cara yaitu guru bisa menerapkan metode bermain sambil belajar supaya siswa tidak bosan selama proses belajar mengajar didalam kelas, menggunakan media pembelajaran yang unik seperti media Alam yaitu melakukan proses pembelajaran IPA dengan melakukan pembelajaran diluar kelas atau langsung belajar dialam terbuka sehingga siswa dapat mengamati alam disekitarnya yang berkaitan dengan pembelajaran IPA. Di dalam pembelajaran IPA siswa akan merasa bosan dan kurang berminat ketika pembelajaran hanya dilakukan di dalam kelas. Pembelajaran IPA memberikan pengetahuan secara langsung agar peserta didik mampu memahami alam sekitar secarai lmiah. Pembelajaran IPA membantu peserta didik untuk memperoleh pemahaman serta diarahkan untuk lebih mengetahui tentang alam disekitarnya.

\begin{tabular}{llccccc}
\hline NO & \multicolumn{1}{c}{ NAMA } & $\begin{array}{c}\text { NO. } \\
\text { INDUK }\end{array}$ & NISN & KELAS & SMT & Nilai \\
\hline 1 & Ade Intan Sari & - & 0089770794 & IX & 1 & 73 \\
2 & Agung & - & 0068745323 & IX & 1 & 77 \\
3 & Aldo Nardo & - & 0072072732 & IX & 1 & 75 \\
4 & Deka Azwahara & - & 0069297650 & IX & 1 & 70 \\
\hline
\end{tabular}




\begin{tabular}{lllllll}
\hline 5 & Dela & - & 0071105154 & IX & 1 & 76 \\
6 & Faiza Arienski & - & 0081655048 & IX & 1 & 78 \\
7 & Ratna Yiliarti & - & 0076491287 & IX & 1 & 77 \\
8 & Tahta Mikdad & - & 0073551660 & IX & 1 & 70 \\
\hline
\end{tabular}

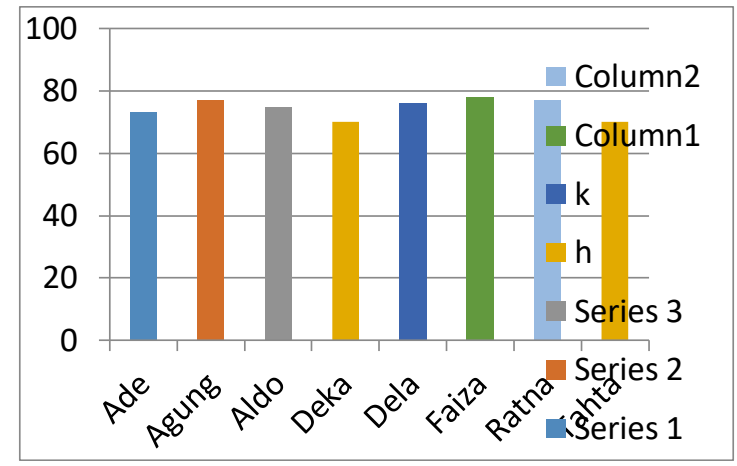

Grafik 2. Hasil Ulangan Tengan Semeter kelas IX di SMPN 3

Tanjung Sakti Pumi Lahat Sumatra Selatan

Dapat dilihat dari hasil nilai ulangan tengah semester yang telah dilaksanakan oleh guru kepada peserta didik SMPN 3 Tanjung Sakti Pumi Lahat Sumatra Selatan bahwa hasil belajar siswa nilai rata-rata kelas yaitu $75 \%$, hasil belajar yang diperoleh dari 8 siswa hanya 5 orang siswa yang sudah mampu mencapai standar rata-rata belajar dan 3 orang siswa yang belum mampu mencapai standar rata-rata belajar.

\section{PENUTUP}

\section{Pelaksanaan}

evaluasi

pembelajaran yang dilakukan di sekolah SMPN 3 Pumi Sakti Lahat Sumatera Selatan evaluasi dalam pembelajaran IPA dilakukan untuk penilaian serta untuk mengetahui sejauh mana keberhasilan siswa dalam mencapai tujuan belajar serta minat siswa terhadap pemebeljaran IPA disekolah. Dan banyak siswa yang tidak berminat karena guru menggunakan metode cerah karena itulah siswa jadi jenuh, siswa akan lebih aktif jika siswa secera langsung terjun kelapangan untuk belajara seperti melakuan observasi pasti siswa bisa memahmi dan minat. belajarnya lebih banyak lagi. Berdasarkan hasil observasi awal yang dilakukan terhadap guru SMPN 3 Pumi Sakti Lahat Sumatera Selatan, dapat diketahui bahwa belajar siswa dilihat dari hasil Ulangan Tengan Semester dilaksanakan. Persentase rata-rata kelas yaitu $75 \%$. Berdasarkan hasil belajar yang diperoleh siswa bahwa dari 8 siswa hanya 5 orang siswa yang mampu mencapai standar rata-rata belajar dan 3 orang siswa belum mampu mencapai standar rata-rata belajar.

\section{DAFTAR PUSTAKA}

Mudakir, I. 2005. Keefektifan Penerapan Model SEQIP dalam Pembeajaran Konsep Dasar IPA di PGSD FKIP UNEJ. Jurnal Pendidikan Dasar, 6(2): 61-118.

Nuriyah, N. 2014. Evaluasi Pembelajaran: Sebuah Kajian Teori Jurnal Edueksos, Vol. III.Hal. 73-86.

Paulson, D.R \& Faust, J.L. 2002. Active Learning For the College Clasroom, http://chemistry. Calstatele. Edu 
Jurnal PTK \& Pendidikan

Vol. 6, No. 2, Hal (66-70)
Dewy Widiyawati, Cici Dwi Putri,

Ahmad Walid

/Chem \& Biochem/

Active/Main.htm.

Paratama, Y. 2001. Pengembangan Model

Sosialisasi Inovasi dan Supervisi

Pembebalajaran Ilmu Pengetahuan

Alam. Disertasikan Doktor.

Universitas Pendidikan Indonesia.

Hal 2.

Zuhud, D. A 1995. Faktor-faktor Kondusif Dalam Mempersiapkan Silabus Dan Materi Proses Belajar Mengajar Bahasa Indonesia Untuk Pnutur Asing. Jakarta: Fakultas Sastra Universitas Indonesia. 